\section{Dr. Eisenberg replies}

\section{To the Editor:}

Firstly, a disclosure. Drs. Urowitz, Gladman, and I have been discussing the optimal way(s) to capture lupus diseases activity since 1986! Sometimes we agree, sometimes not; but we try hard to keep it good-natured.

Their letter ${ }^{1}$, with due respect, does not really address the concerns expressed in my editorial ${ }^{2}$ : that the Systemic Lupus Erythematosus Disease Activity Index 2000 Responder Index-50 (S2K RI-50) does not capture those patients whose symptoms which, having developed, then at the next assessment have got worse. Patients coming into clinical trials with, let us say, active arthritis or pleuritic pain will clearly get points on Systemic Lupus Erythematosus Disease Activity Index 2000 (SLEDAI-2K) or S2K RI-50, but neither index will identify those patients given drugs and whose arthritis/pleuritis has deteriorated, or distinguish them from those whose symptoms have partially improved (by, let us say, $25 \%$ ), or remained the same. That is the problem.

My friends and colleagues also miss the point about the British Isles Lupus Assessment Group index (BILAG)! Its scoring may be a little complex (although because, in clinical trials or on routine followup, the computer software does this, even scoring is not much of an issue). Further, the premise of BILAG, i.e., to ask patients with SLE, "Do you have a $\mathrm{rash} / \mathrm{joint}$ problem/central nervous system feature etc., etc., and if you do, how has it been over the last month, better/worse/same?" is both simple and intuitive. BILAG provides a more comprehensive capture of SLE features than $\mathrm{SLEDAI}^{3}$, and if there is a need for metrics - well, they are available, using the validated conversion $\mathrm{A}=12, \mathrm{~B}=8, \mathrm{C}=1, \mathrm{D} / \mathrm{E}=0$, for the BILAG 2004 index ${ }^{4}$.

DAVID A. ISENBERG, MD, FRCP, FAMS, Arthritis Research UK Diamond Jubilee Professor of Rheumatology at University College London, The Rayne Building, 4th Floor, Room 424, 5 University Street, London WC1E 6JF, UK. E-mail: joan.perry@ucl.ac.uk

\section{REFERENCES}

1. Touma Z, Urowitz M, Gladman D. Systemic Lupus Erythematosus Disease Activity Index 2000 Responder Index-50 website. J Rheumatol 2013;40:733-4.

2. Isenberg DA. Rhubarb and reliability - A Jane Austen view of systemic lupus erythematosus [editorial]. J Rheumatol 2013;40:7-8.

3. Yee CS, Isenberg DA, Prabu A, Sokoll K, Teh LS, Rahman A, et al. BILAG-2004 index captures systemic lupus erythematosus disease activity better than SLEDAI-2000. Ann Rheum Dis 2008;67:873-6.

4. Yee CS, Cresswell L, Farewell V, Rahman A, Teh LS, Griffiths B, et al. Numerical scoring for the BILAG-2004 index. Rheumatology 2010;49:1665-9.

J Rheumatol 2013;40:5; doi:10.3899/jrheum.130070 
Cutaneous Manifestations and Comorbidities in 60 Cases of Takayasu Arteritis

Rocha KL, Romitti R, Shinjo S, Neto ML, Carvalho J, Criado

P. Cutaneous manifestations and comorbidities in 60 cases of

Takayasu arteritis [letter]. J Rheumatol 2013;40:734-8. The author's full name should be given: Paulo Ricardo Criado. We regret the error.

doi:10.3899/jrheum.121276.C1 